\title{
Research on the Problems and Countermeasures of Practical Teaching in the NCO Academy
}

\author{
Xiaojia Gu, Zhongmin Liu, Zelong Zhou, Yun Liu, Qiong Zou \\ Wuhan Mechanical College, Army Engineering University, Wuhan, 430075, China
}

Keywords: NCO Academy, Practical teaching, Countermeasures

\begin{abstract}
Practical teaching is an important link in the teaching of the Academy of sergeant. It is a major issue for the professional education of the sergeant to study and reform the practical teaching. This paper analyzes the main problems and causes of practical teaching in the current NCO academies, and puts forward the corresponding solutions and countermeasures.
\end{abstract}

\section{Analysis on the main problems and reasons of practical teaching in the Academy of sergeant}

Since the start of the first sergeant school in 1986, the sergeant education came into being. Due to the lack of mature theory, some education and teaching methods can only be explored according to the needs of the army and the experience of traditional education. After more than 30 years of exploration and practice, the theory of sergeant education is becoming more and more mature, the idea is gradually clear, and the new educational concept has infiltrated into the educational reform. Under the guidance of training objectives of NCO talents, all sergeants colleges are constantly strengthening practical teaching links, increasing practical teaching reform, and constantly improving the practical teaching system. However, influenced by traditional education mode, the practical teaching system of NCO is not scientific and reasonable at present, which affects the quality of personnel training in NCO academies.

Firstly, the practical teaching system is not reasonable.

At present, there are many unreasonable problems in practice teaching system in non commissioned colleges, such as unreasonable practice courses, low proportion of practice teaching in course teaching, insufficient total time of practice teaching, lagging behind of practical teaching content and so on. A Naval Electronic Warfare Officer School as an example, the professional set up a total of 19 courses, of which the ideological and political courses and 10, accounting for $47.6 \%$; professional course 9, accounting for $42.8 \%$; practice class 2, accounting for 9.5\%; the overall proportion of practice teaching and theory hours about 3:7. This situation leads to heavy theory and light practice, disjointed theory with practice, and does not adapt to the training goal of the sergeant. In addition, in recent years, the army's weaponry and equipment have developed rapidly, and the troops have accelerated and eliminated a large number of old equipment and installed a large number of new weapons and equipment. The speed of updating the content of practical teaching can not keep up with the new situation of rapid development of equipment, which makes it impossible to learn and learn.

The emergence of this problem is due to the unreasonable design of top-level teaching in the practice teaching of non commissioned colleges. The fundamental reason is that the sergeant academy failed to carry out the top-level design of practical teaching based on the training objectives of NCO officers. Personnel training objectives should be familiar with the army work work processes, work skills and mastery of your job skills by completing tasks, learning technical skills related to the job of students self-learning ability cultivation of comprehensive ability, and the ability to cooperate with others, to achieve the job. NCO colleges should integrate the training objectives of NCO talents into the formulation of practical teaching plans, syllabus and curricula, and become the fundamental basis for organizing practical teaching.

Secondly, layered training requirements failed to effectively implement.

The sergeant colleges and universities have many training levels, and the training tasks are heavy. 
The Army Ordnance Officer School Engineering University as an example, the school has undertaken covering occupation technology education, training, and early pre Sergeant Shanxi Shanxi high upgrade training, new equipment and technology backbone rotation, high skilled personnel training, joint military training officers, working skills training eight different types of training tasks. The levels of students practice teaching content and mode should be effectively defined and distinguished, but from the actual operation situation, teaching practice between different training levels, whether teaching mode, training subjects or training requirements exist to varying degrees of duplication and repetition, there is no hierarchical pot teaching phenomenon.

The emergence of this phenomenon is mainly due to the following two aspects. First, we need to analyze and grasp the training objectives, characteristics and rules of different training levels at colleges and universities, and fail to design differentiated practical teaching system according to different levels of NCO students' future job tasks. The two is on the professional level and practical conditions of construction is not perfect, not for all levels of the professional training needs of the construction of independent supporting training textbooks, exam and training facilities such as hardware and software conditions, or even a set of individual professional training materials in a training database baodatianxia.

Thirdly, lack of teaching ability in teaching staff.

The post position of the officers of the sergeant needs to require the sergeant education to adhere to the principle of ability standard, and to highlight the training of the ability. To train NCO talents, they have more skillful professional skills. Teachers not only need solid professional theoretical basis, but also have excellent professional skills, practical skills and a set of teaching methods suitable for skills training. However, there is still a gap between the status of NCO teachers and the training requirements of high-quality NCO talents. The contradiction between professional skills, professional hands-on ability and teaching needs is outstanding. Not only the ability of basic class teachers is not strong, but also there is this problem in the professional teaching staff.

This situation is not only the result of the influence of the traditional educational concept which pays attention to the teaching of theoretical knowledge, but also determined by the source of the Sergeant Staff. In recent years, the army, young teachers colleges lack of military practice in their life, do not understand the forces, not familiar with the officers, not enough grasp of new equipment, new tactics, practice ability is weak, in the process of teaching, more emphasis on imparting knowledge, but not for non commissioned officers of the post requirement, effective training comprehensive quality and practice ability of students.

Fourthly, unscientific assessment and evaluation of practical teaching.

At present, there are two main problems in the evaluation and evaluation of practical teaching in the Academy of sergeant. First, the evaluation standard is not reasonable, and the standard of evaluating the students of different levels of sergeant is the same. Two, the evaluation method is single, qualitative assessment is more than quantitative evaluation, results are heavier than the process, which is not conducive to comprehensive and real assessment of NCO students' knowledge, skills and innovation ability.

The cause of this problem is a kind of occupation skill and ability standard Sergeant colleges lack of systematic research, no real from all levels of job demand, develop the practical skills necessary to perform their tasks and assessment project appraisal standards, the practical skills examination project and the standard largely identical; on the other hand and most of the current practice of teaching evaluation with summative evaluation, resulting in the vast majority of sergeant students do not usually pay attention to the accumulation of knowledge, the comprehensive ability of cadet is not improved.

Fifthly, the practical teaching is not suited to the practical teaching requirements

At present, the practical teaching of various majors in NCO academies is still designed according to the discipline knowledge system rather than the needs of NP students' future job tasks, and the contents and locations of practical teaching are designed. 


\section{The countermeasures to reform the practical teaching of the Academy of NCO}

Firstly, improve the top level design and optimize the practical teaching course and content system.

In the practical teaching of the top-level design, to effectively fulfill the actual conditions of post ability as the goal, to highlight the individual quality and the team with the military skill training, outstanding political work ability and psychological quality of political work skills training, equipment operation and maintenance of the outstanding professional skills training, so that students in the plan and improve the quality of practice of teaching objectives, training. In the design of practical curriculum system, we should establish curriculum standards based on post needs, and refine and decompose talents training objectives, and integrate them into courses, so as to achieve a comprehensive link between curriculum setting and personnel training objectives. When designing practical teaching contents, we should arrange the whole practice teaching content according to the general objectives of the practical courses, and arrange the specific contents of each implementation, which includes both teachers' teaching objectives and students' learning goals. In addition, the teaching contents should be optimized in some practical courses, the basic theory and case study, want to work the content of organic integration, the formation of practical teaching contents, reasonable system structure.

Secondly, classifying teaching according to different training levels.

According to the training characteristics and requirements of different levels of students, implementing classified teaching is the basic requirement of post education and the fundamental instruction of practical teaching. One is to teach according to the present situation of the ability of the object of education. Cadet forces work in different levels, learning time length, the length of time the army has the ability of showing significant differences. Aiming at the current situation of NCO students in different levels, it is an important way to improve practical teaching effectiveness of NCO academies by scientifically selecting training materials and practical subjects. The two is to teach according to the post responsibility of the multi level sergeant. According to the post responsibilities and tasks of different levels of NCO students after graduation, the sergeant colleges and universities should draw up a training roadmap for professional post competency training, and make reasonable matching and effective distinction in practical teaching contents, subjects and evaluation criteria.

Thirdly, establish a scientific and effective practical teaching evaluation system.

The establishment of a scientific and complete practical teaching evaluation system is the main means of attaching importance to practical teaching and promoting the rapid improvement of the quality of practical teaching. Whether the results of assessment and evaluation are objective and impartial is mainly dependent on the establishment of a comprehensive evaluation index system of practical teaching. First, make clear the goal of practical teaching management evaluation. Based on different training levels, talent training programs and curriculum standards, we should conclude and evaluate key elements that reflect the competency of NCO posts. Second, analyze the evaluation factors of practice training. According to the purpose of practical teaching evaluation, we collect data and data centrally, conduct a comprehensive analysis of all elements of practice teaching system, and grasp the main factors of practical teaching. For the practice of professional skills, we should seriously consider the teaching objectives of practical skills and analyze the various relationships among the elements of practical skills. Third, to determine the practice teaching index system of management evaluation. The index is the specific symbol to measure the practice teaching. For the evaluation of the practice teaching system, we must establish a unified scale that can be compared and measured, that is, the practical teaching price index system. Fourth, to formulate practical teaching evaluation methods and evaluation criteria. In the practice of teaching evaluation, scientific evaluation must follow a combination of qualitative and quantitative, process and results of a combination of the qualitative quantitative description index to quantify, highlight the process evaluation of the subject status, such as perfecting the amendment professional solution, standard professional skills identification. 
Fourthly, strengthen the construction of the "double teacher type" teaching staff.

Practical teaching transforms knowledge into application characteristics, which determines that teachers in practice teaching must have solid theoretical knowledge and rich practical experience. Building a "double quality" faculty team is an inevitable requirement for the development of NCO vocational education. Need to vigorously promote the following aspects from the academy teachers of "double teacher type" construction: the first is to promote the ability of teachers to the field army officer school professional counterparts post regular exchanges; the two is to increase the NCO school teacher training, improve the sergeant school teacher's theoretical level and practical ability through on-the-job training, job training, in a variety of ways to communicate. The three is to strengthen the construction of the system and promote the transformation of the "double teacher" to the "double certificate" in the sergeant school.

Fifthly, strengthen the construction of practical teaching conditions on the battlefield.

Strengthening the construction of practical teaching conditions close to the battlefield is the inevitable requirement of developing practical teaching. We should plan the training base construction both inside and outside the school, and make rational layout, and establish effective operation mechanism. One is to make full use of military resources, strengthen the school and the army cooperation, building the base of practice, so that students in the professional theory learning stage can directly contact the actual equipment, familiar with the job; two is to combine the school in office building built school training venues, in order to improve the post office ability as the main line, for equipment for jobs, tightly focusing on the needs of the needs of troops and equipment development, build a real working environment or simulation of the battlefield environment, to achieve seamless learning and post. The intern practice field and the outside school practice base should form a practical teaching network which is mutually supportive, complementary and open to each other.

\section{Conclusion}

In short, petty officer education, as a typical military vocational education, has dual characteristics of military education and vocational technology education. Therefore, we must learn from and absorb Local Vocational Technology Based on the practice of our NCO education.

\section{References}

[1] Su Qunxing, Wei Zhigang. Research on the education reform and development of sergeant[M]. Beijing: Liberation Army press.2013.

[2] Zhang Bei, The theory and practice of sergeant education [M]. Beijing: National Defense Industry Press.2008.

[3] Li Yongfeng. A brief discussion on the reform of the post of sergeant service education[J]. new generation.2010 (10): 76.

[4] Shi Yanbo. A brief discussion on the characteristics and development trend of sergeant post education[J]. legal system and social.2010 (3): 12-13 